\title{
Virtue of Patience in Surgery
}

\author{
R. V. Nataraj, M. Pandare, S. Bage, M. Jagade, R. Kar, K. Parelkar \\ Department of Otorhinolaryngology and Head \& Neck Surgery, Grant Government Medical College and Sir J.J. \\ Group of Hospitals, Mumbai, India \\ Email: nataraj.rv@gmail.com
}

Received 8 June 2014; revised 7 July 2014; accepted 5 August 2014

Copyright (C) 2014 by authors and Scientific Research Publishing Inc.

This work is licensed under the Creative Commons Attribution International License (CC BY).

http://creativecommons.org/licenses/by/4.0/

(c) (i)

\begin{abstract}
Managing cut throat injuries are a challenge as it may involve the three anatomical components of the neck namely vascular component, which involves carotid arteries, jugular veins, subclavian vessels and the vertebral arteries; respiratory component, which involves larynx and trachea and digestive component, which involves pharynx and esophagus. Injury to one or more of the components may lead to profuse hemorrhage from injured major blood vessels, air embolism and airway obstruction. Managing electrical cut throat injuries to neck are particularly challenging because of the damage that occurs at cellular level. We hereby report a case of electrical cut throat injury to neck.
\end{abstract}

\section{Keywords}

\section{Electrical Cut Throat Injury, Cut Throat Injury, Collagen Dressing, Patience}

\section{Introduction}

With high-voltage injuries, most of the injury appears to be thermal and most histologic studies reveal coagulation necrosis consistent with thermal injury [1]. Lee et al. [2] proposed the theory of electroporation that electrical charges, which are too small to produce thermal damage, cause protein configuration changes that threaten cell wall integrity and cellular function. This is a case report of a large and infected electrical cut throat injury to neck whose surgical outcome was excellent due to regular dressing and use of gamma sterilized collagen particles for the wound prior to surgery.

\section{Case Report}

A 21-year-old male manual laborer, suffered from electrocution injury to neck when he came in contact with a live wire on 13/09/13 resulting in a large open wound in the neck. He was admitted in a nearby private hospital in a cyanosed and breathless state where an emergency tracheostomy was performed on the same day, a Portex 
tracheostomy tube was inserted and the neck wound was sutured.

During the post operative period the patient was not kept nil per oral and was started on liquid diet on $1^{\text {st }}$ post operative day and on semi solid diet on $2^{\text {nd }}$ post operative day. Right from the $1^{\text {st }}$ post operative day the patient complained of soakage of the dressing with ingested water and food particles. On $3^{\text {rd }}$ post operative day the wound dressing was removed to reveal dehiscence of the wound with active and profuse pus discharge along with presence of food particles on the wound \& dressing. The wound was redressed and a metallic tracheostomy tube was inserted. Following day the patient was discharged and referred to higher centre for further management.

When the patient visited E.N.T. OPD of Sir J.J. Group of Hospitals, the above mentioned history was noted and examination of the patient revealed following findings.

- Patient was febrile with temperature of $104^{\circ} \mathrm{F}$.

- Metallic tracheostomy tube number 32 in situ with good air blast.

- An wound of size $6 \times 2 \times 2 \mathrm{~cm}$ with profuse slough extending superiorly up to lower body of hyoid bone, inferiorly to the arch of cricoid cartilage, medially to $4 \mathrm{~cm}$ lateral to midline at the level of lower border of body of hyoid bone and laterally to medial border of middle $1 / 3^{\text {rd }}$ of left sternocleidomastoid muscle (Figures 1-3).

- Both the laminae of the thyroid cartilage were exposed.

- The Cricothyroid muscle was exposed.

- Laryngeal inlet and laryngeal lumen was exposed and was covered in slough.

- Dribbling of water from the wound was noticed when the patient was asked to drink few sips of water. An urgent CECT Neck was done and following findings were reported.

- Discontinuity of skin, subcutaneous tissue and infrahyoid muscle in anterior and lateral region of neck, more on left than right, at the level of hypopharynx and defect in the left anterolateral wall of hypopharynx with resultant exposure of the hypopharynx to the exterior (Figure $4 \&$ Figure 5).

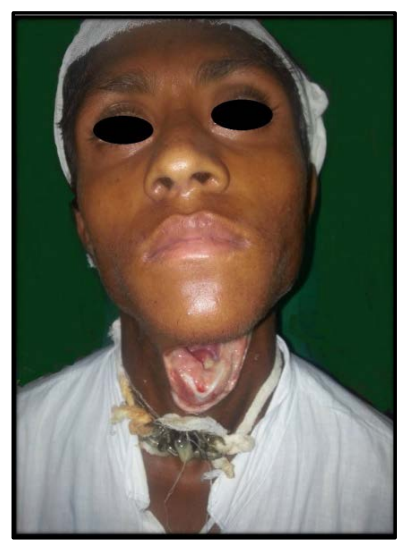

Figure 1. State of the wound upon admission.

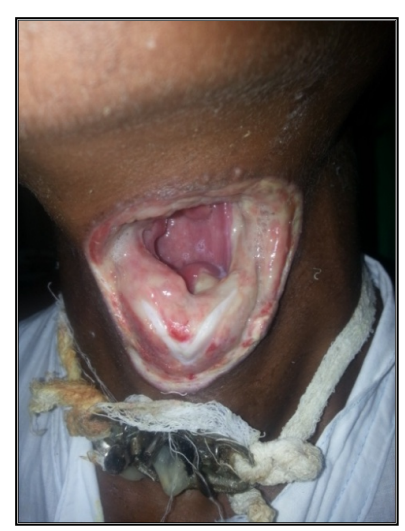

Figure 2. A large infected wound over left side of neck. 


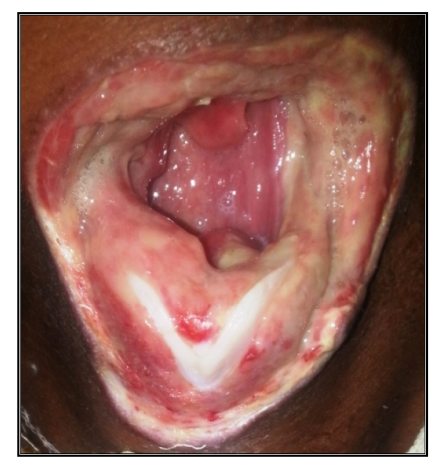

Figure 3. Hypopharynx was exposed to exterior.

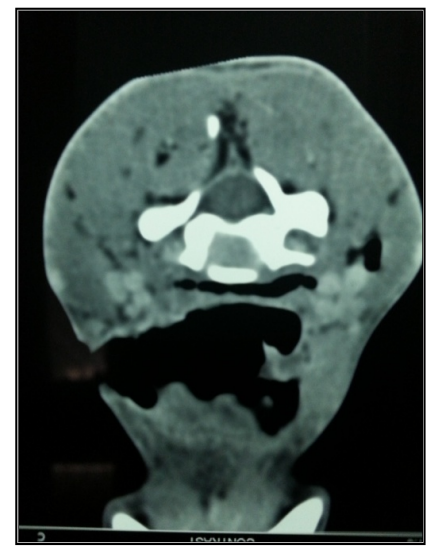

Figure 4. CT scan neck $(\mathrm{P}+\mathrm{C})$.

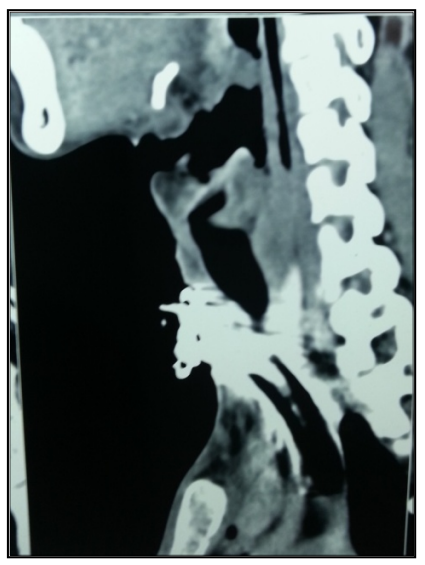

Figure 5. CT neck $(\mathrm{P}+\mathrm{C})$.

- Deviation of epiglottis to right with disruption of left pharyngo-epiglottic fold.

- Extensive subcutaneous emphysema extending from skull base to thoracic inlet in thorax.

Upon admission, Ryle's tube of size 16 was inserted and high protein diet via Ryle's tube was started. The wound was managed by regular and twice a day dressing with Normal Saline, Eusol solution and Betadine solution under an antibiotic coverage for Gram positive \& Gram negative and anaerobic bacteria. This line of therapy was rigorously followed and after one week the patient showed marked improvement. The slough dried off and granulation tissue was noticed growing on the periphery of the wound.

But after one more week of the therapy, the rate of granulation tissue growth was noticeably slow and disap- 
pointing. In order to speed up the healing process, application of gamma sterilized collagen particles was initiated.

Collagen helps in all stages of wound healing [3]-[5].

1) Hemostatic phase-The collagen particles are chemotactic to platelets attract the platelets towards the wound site. This causes aggregation of the platelets at the wound site, formation of platelet plug and thus hemostasis is achieved.

2) Inflammatory phase-The inflammatory cells at the wound site secrete various kinds of proteolytic enzymes. Collagen particles are degraded by these enzymes into protein fragments or peptides. Peptides, in turn, attract variety of cells like mononuclear cells, macrophages and monocytes. These cells simulate collagen synthesis and promote organized deposition of the newly formed collagen.

3) Proliferative phase.

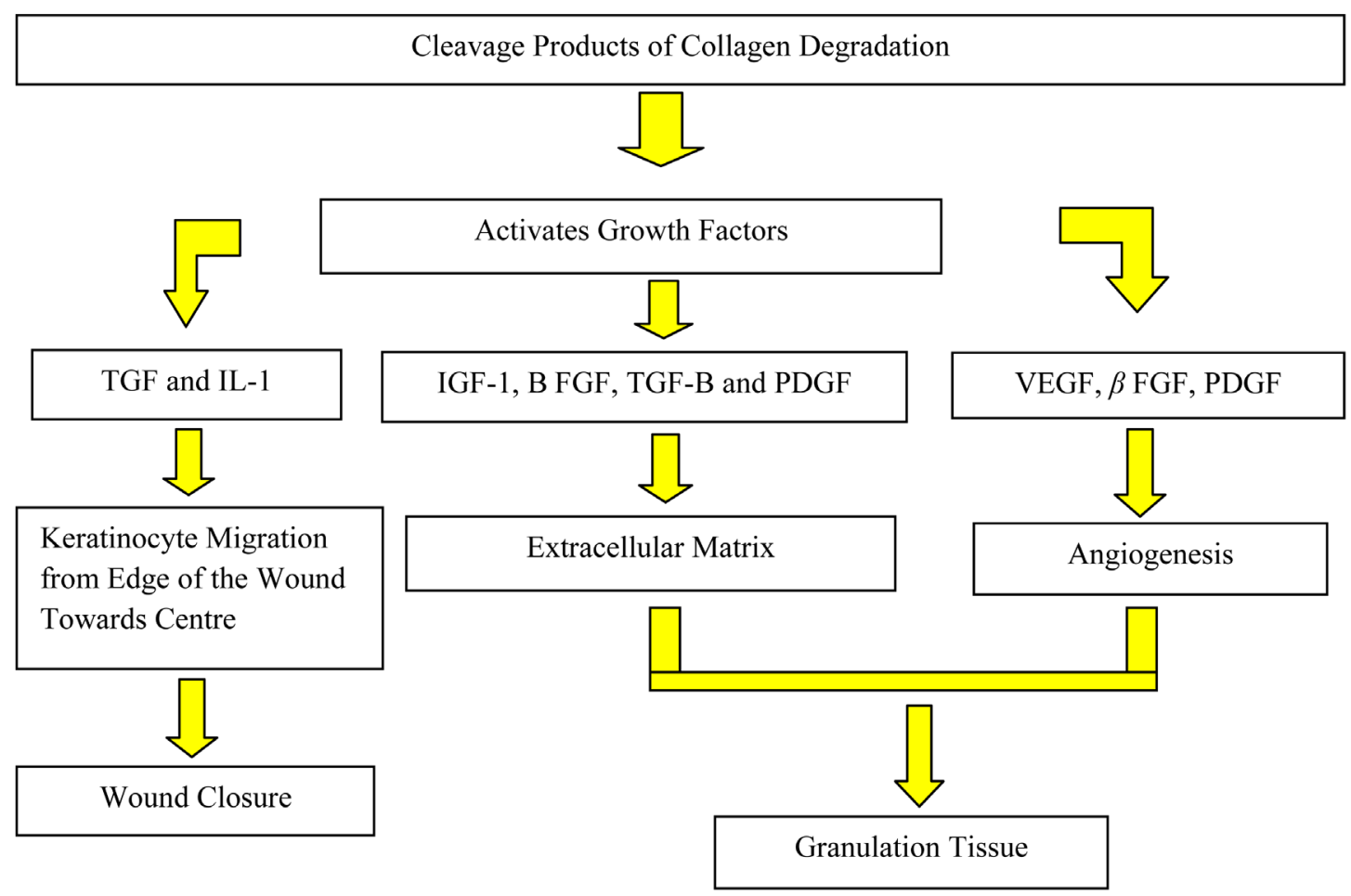

4) Remodelling phase-In this phase, the collagen fibers undergo extensive cross linking to form a strong scar.

Within few days of use of collagen particles, rapid growth of the granulation tissue was noticed. After three weeks of regular usage, the entire thyroid cartilage and the Criocothyroid muscle was covered with granulation tissue. The laryngeal opening was almost closed and the patient was able to swallow the saliva. Weaning of tracheostomy tube was from $24^{\text {th }}$ day of admission and decannulated on $28^{\text {th }}$ day without any respiratory distress.

Picture of the wound taken at weekly intervals demonstrates the progression of the healing process (Figures 6-11).

The skin defect was then closed on $49^{\text {th }}$ day by V-Y plasty technique (Figure 18). His post operative recovery was uneventful. Strict neck flexion was maintained for 10 days with help of customized neck collar. Fibreoptic laryngoscopy and bronchoscope was done on $7^{\text {th }}$ post operative day. The larynx was found to be normal. A thin neat scar can be seen at the sutured site without any stenosis. Comparative CT Scans show complete healing of the wound without any evidence of residual defect or fistula (Figures 12-18).

\section{Discussion}

In case of cut throat or penetrating injuries of neck, one should keep in mind the possibility of following vital structures being injured like larynx, pharynx, trachea, oesophagus, major neck vessels, nerve roots and spinal cord. Clinical examination and investigations should aim towards detecting any injury to these structures. Blood 


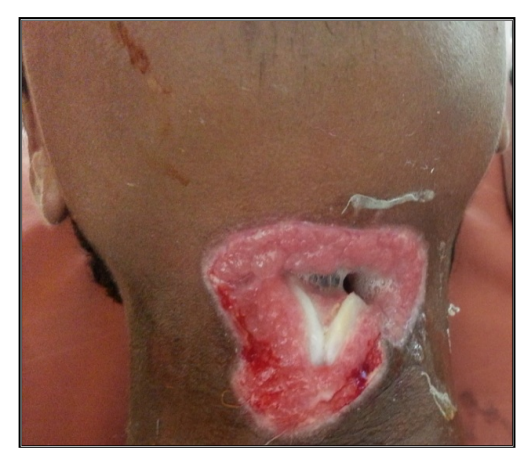

Figure 6. After 2 weeks.

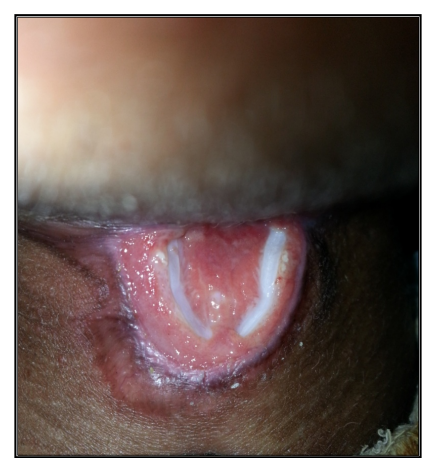

(a)

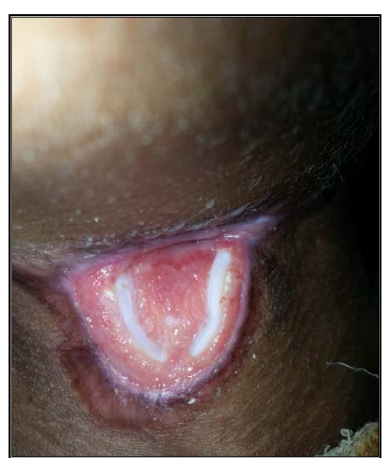

(b)

Figure 7. (a) (b) After 3 weeks.

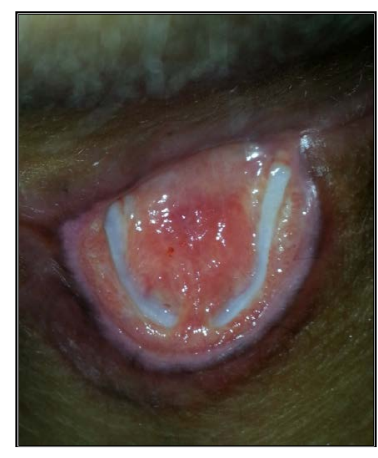

(a)

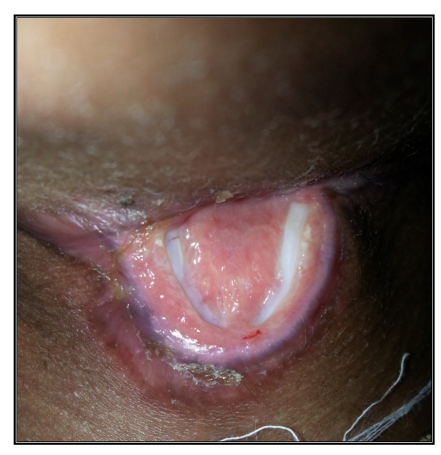

(b)

Figure 8. (a) (b) After 4 weeks.

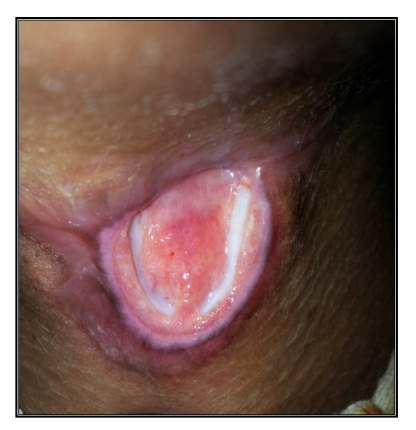

(a)

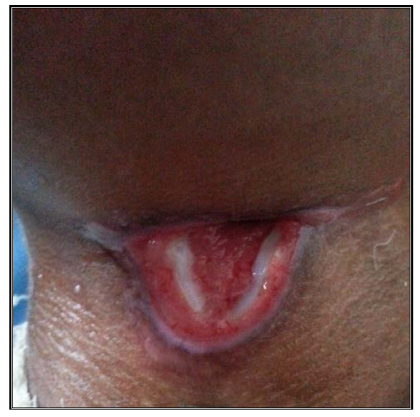

(b)

Figure 9. (a) (b) After 5 weeks. 


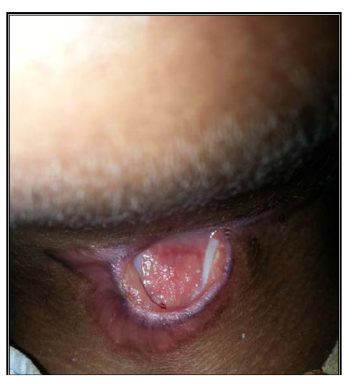

(a)

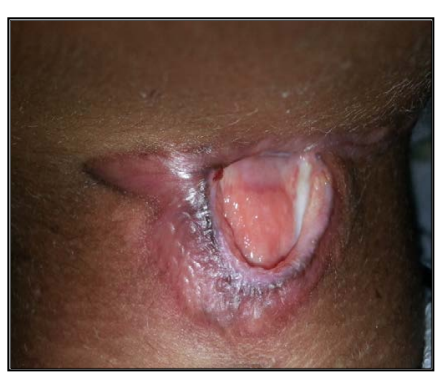

(b)

Figure 10. (a) (b) After 6 weeks.

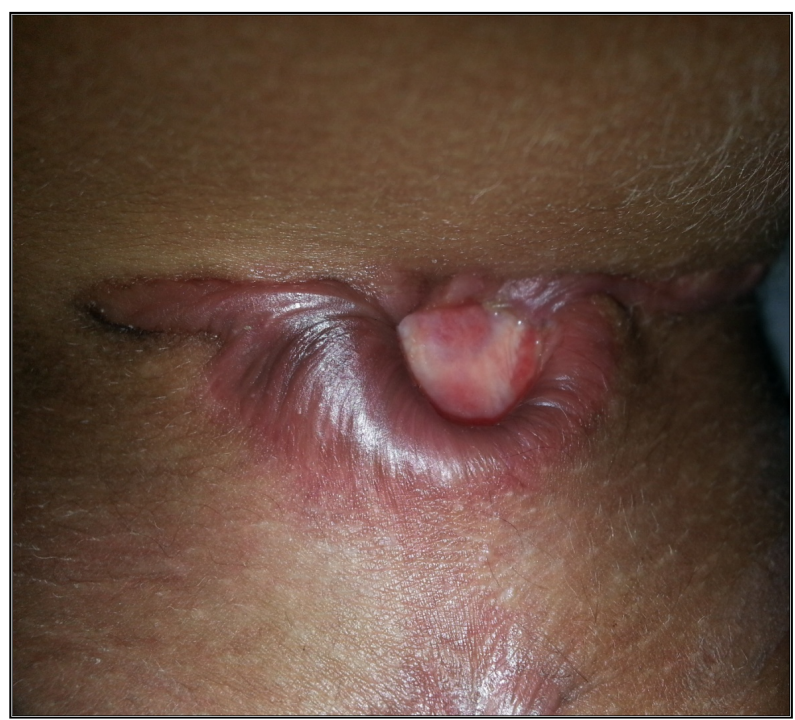

Figure 11. The $7^{\text {th }}$ week.

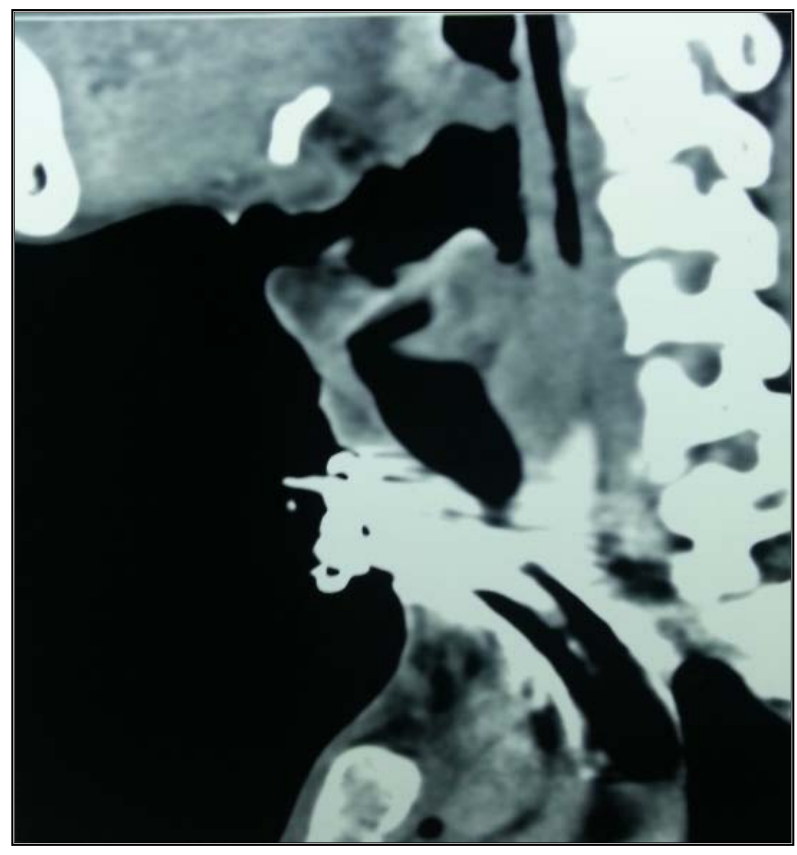

Figure 12. CT neck before. 


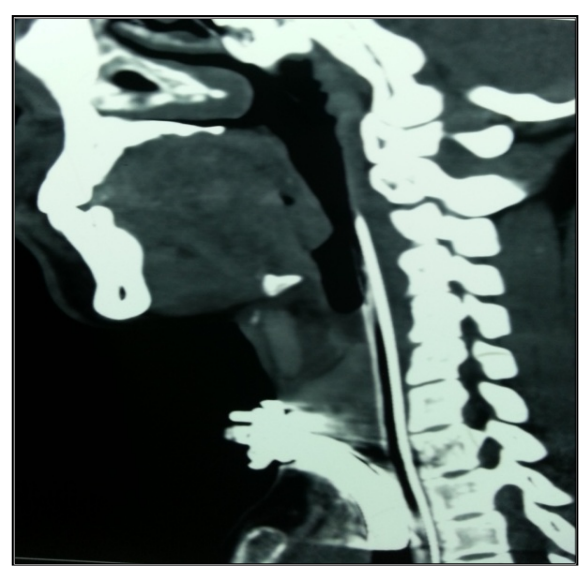

Figure 13. CT neck after.

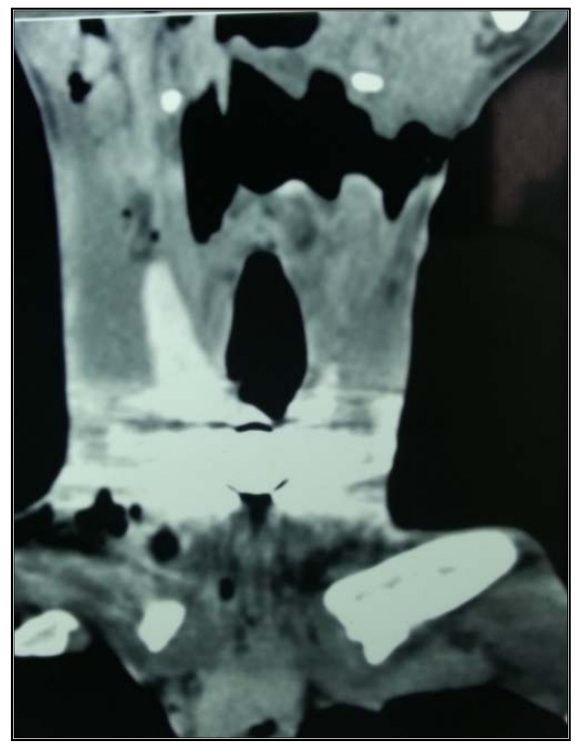

Figure 14. CT neck before.

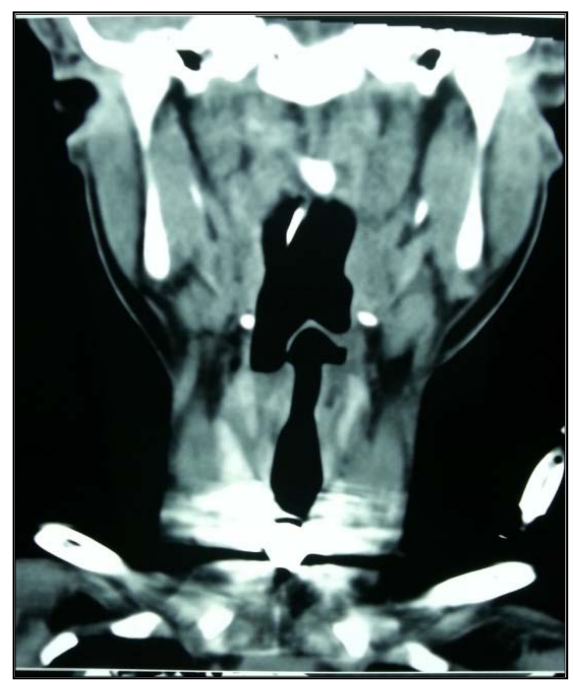

Figure 15. CT neck after. 


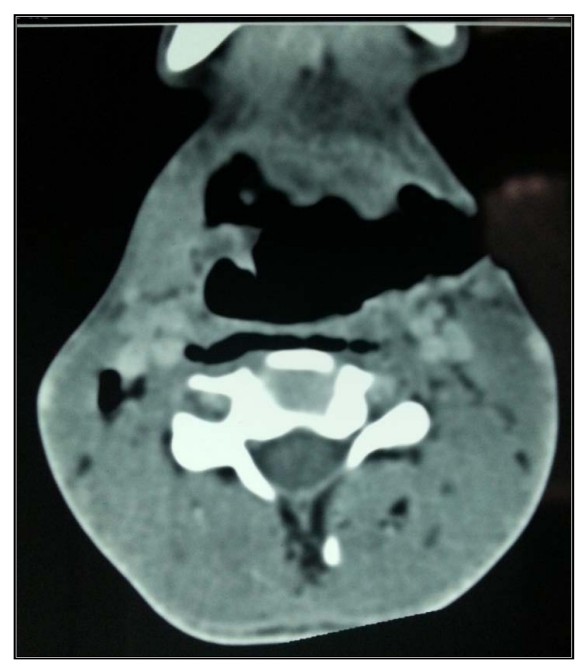

Figure 16. CT neck before.

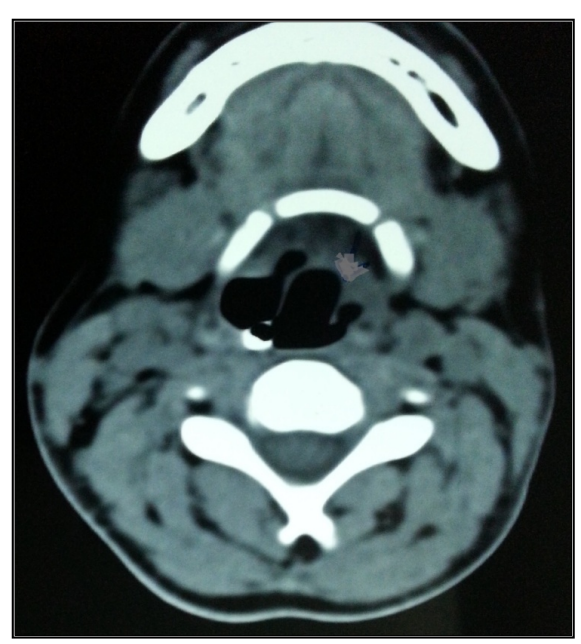

Figure 17. CT neck after.

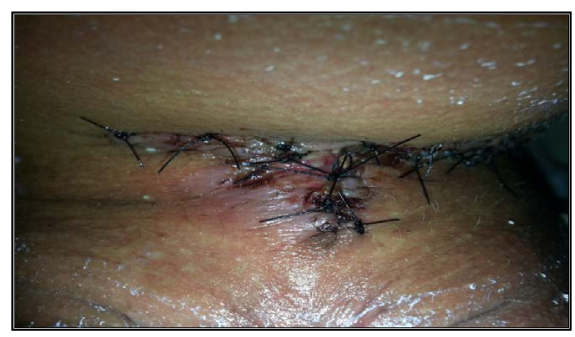

Figure 18. After primary closure.

tests (urgent packed cell volume, urea and electrolyte levels), angiography, endoscopy (esophagoscopy, microlaryngoscopy and bronchoscopy) and computerized tomographic (CT) scan helps to determine the extent of injury. Individuals are transfused with whole blood depending on the extent of blood loss. Plain radiography alone is not sufficient to diagnose airway trauma and the additional use of dynamic CT scan of the trachea and larynx and magnetic resonance imaging (MRI) can be very helpful in discovering previously undetected injuries, showing that some of these injuries may not even require surgical intervention.

In the event of late presentation, such as this case, debridement of infected tissues prior to suturing is a norm. But debridement may also mean loss of substantial amounts of tissue to effect simple and proper closure. Con- 
servative debridement coupled with regular diligent dressing and [6] use of collagen particles not only helps in normalizing the local environment but also helps in growth of new tissue. As a result, the ease and efficacy of wound closure are increased and risk of post operative infection and wound dehiscence is also minimized.

\section{References}

[1] Le May, S.R. (1971) Penetrating Wounds of the Larynx and Cervical Trachea. Archives of Otolaryngology, 94, 558565. http://dx.doi.org/10.1001/archotol.1971.00770070858011

[2] Lee, R.C., et al. (1988) Role of Cell Membrane Rupture in the Pathogenesis of Electrical Trauma. Journal of Surgical Research, 44, 709-719. http://dx.doi.org/10.1016/0022-4804(88)90105-9

[3] Lazovic, G., Colic, M., Grubor, M. and Jovanovic, M. (2005) The Application of Collagen Sheet in Open Wound Healing. Archive of Annals of Burns and Fire Disasters, 18, 151-156.

[4] Nataraj, C., Ritter, G., Dumas, S., Helfer, F.D., Brunelle, J. and Sander, T.W. (2007) Extra Cellular Wound Matrices: Novel Stabilization and Sterilization Method for Collagen-Based Biologic Wound Dressings. Wounds, 19, 148-156.

[5] Motta, G., Ratto, G.B., De Barbieri, A., Corte, G., Zardi, L., Sacco, A., et al. (1983) Can Heterologous Collagen Enhance the Granulation Tissue Growth? An Experimental Study. The Italian Journal of Surgical Sciences, 13, 101-108.

[6] Bhattacharya, S., Tripathi, H.N., Gupta, V., Nigam, B. and Khanna, A. (2011) Collagen Sheet Dressings for Cutaneous Lesions of Toxic Epidermal Necrolysis. Indian Journal of Plastic Surgery, 44, 474-477. http://dx.doi.org/10.4103/0970-0358.90826 
Scientific Research Publishing (SCIRP) is one of the largest Open Access journal publishers. It is currently publishing more than 200 open access, online, peer-reviewed journals covering a wide range of academic disciplines. SCIRP serves the worldwide academic communities and contributes to the progress and application of science with its publication.

Other selected journals from SCIRP are listed as below. Submit your manuscript to us via either submit@scirp.org or Online Submission Portal.
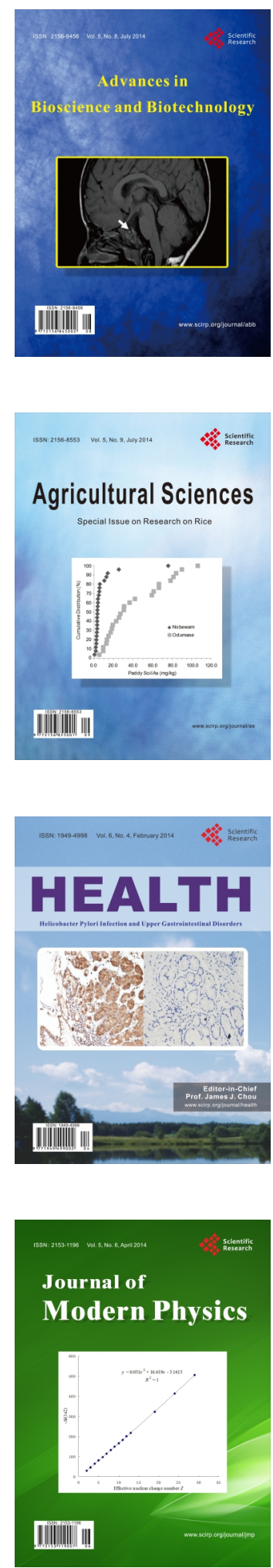
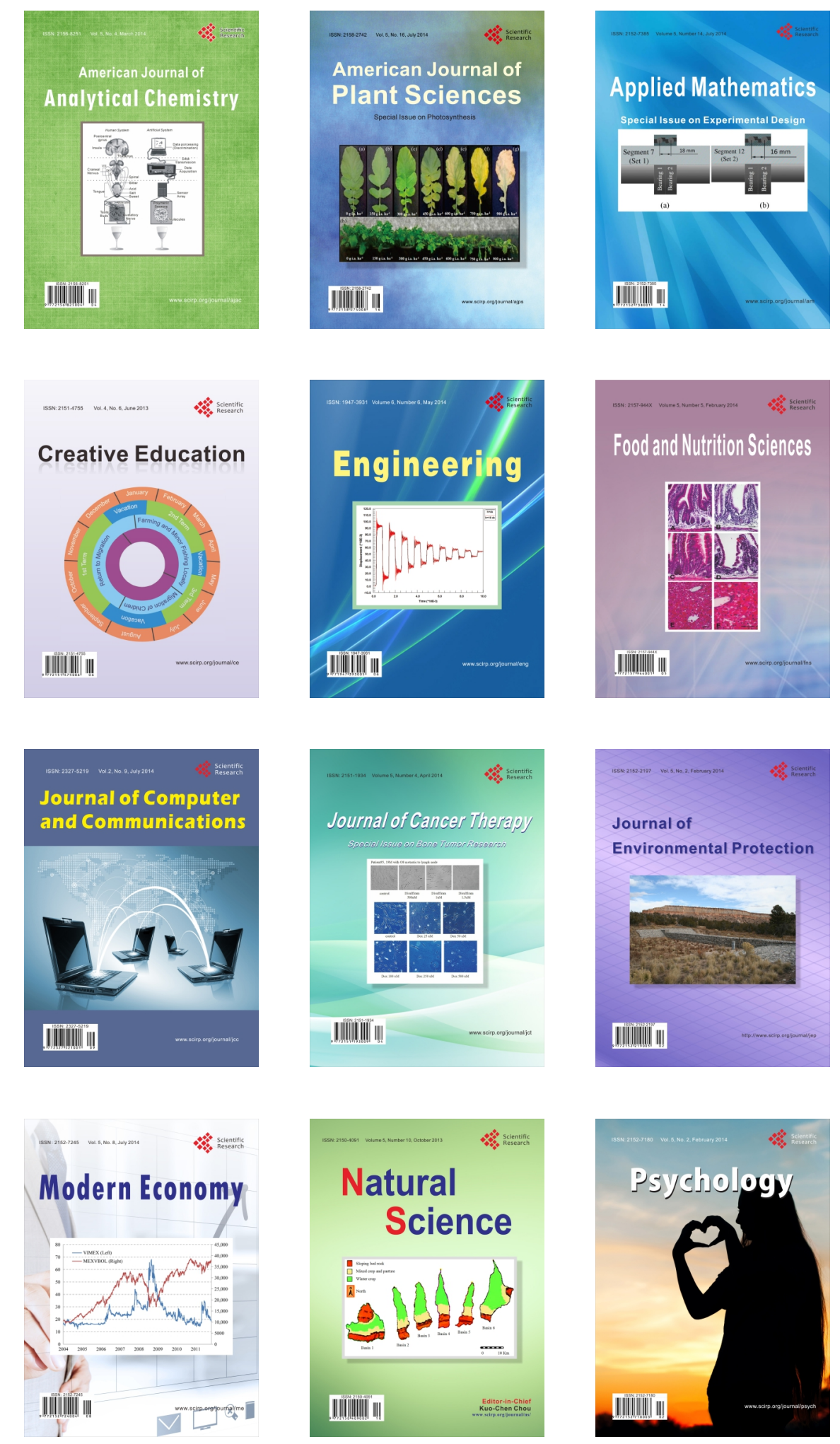